\title{
As disputas discursivas por identidade racial en dois seriados televisivos brasileiros
}

\section{Nelson Rosário de Souza* \\ Daniela Rocha Drummond* \\ Viritiana Aparecida Almeida*}

\section{Resumo}

A presente análise elegeu como objeto as duas séries de televisão brasileiras Sexo e as Negas e Mister Brau. A primeira retrata a intimidade de quatro mulheres negras da periferia urbana, destacando o protagonismo delas quanto à sexualidade. A segunda tematiza a ascensão social de um jovem casal de negros a partir do sucesso musical. Em ambas aparecem tensões interseccionais de raça, classe e gênero que pedem uma perspectiva não essencialista que valorize as interações entre mídia e sociedade. A questão central do estudo é: quais tensões e contradições podem ser apreendidas nos conteúdos dos seriados, comparativamente, quando se observa as linhas discursivas sobre raça e gênero que eles mobilizam? Os seriados conferem protagonismo aos afrodescendentes, entretanto, linhas discursivas associadas à subalternização são reproduzidas, mas não sem resistências.

Palavras-chave: seriados de TV, Mister Brau, Sexo e as Negas, identidade racial, disputas discursivas.

* Universidade Federal do Paraná, Curitiba, PR, Brasil. 


\section{The discursive disputes regarding racial identity in two Brazilian TV series}

\section{Abstract}

This paper analyses two Brazilian television series, namely Sexo e as Negas and Mister Brau. The first one portrays the intimacy of four black women from the slums, highlighting their sexuality. The other series, called Mister Brau, had as its main theme the social ascension of a couple who acquired fame from popular music. Both shows address intersectional issues such as race, social class, and gender, which require a non-essentialist perspective that values interactions between media and society. The main question is: what tensions and contradictions can we apprehend in these series' content, relatively, regarding the discursive lines about racial and gender issues? The shows have people of African descent as their protagonists, however, discursive lines associated with subordination are reproduced, though not without resistance.

Keywords: TV series, Mister Brau, Sexo e as Negas, racial identity, discursive disputes.

\section{Introdução}

comparação entre os programas televisivos Sexo e as Negas (SN) e
Mister Brau (MB) se justifica, pois ambos interagem com a herança
discursiva brasileira sobre raça e gênero; são séries produzidas pela Rede Globo de Televisão e se aproximam da comédia de situação (Esquenazi, 2011). Entretanto, são programas que aproveitam características dos bem-sucedidos folhetins brasileiros, propondo, por exemplo, assuntos cotidianos e temas sociais, e prezam pela verossimilhança. A queda no interesse pelas telenovelas está relacionada com a renovação dos seriados norte-americanos (Hamburger, 2011), fenômeno que influenciou a produção de seriados nacionais.

O programa SN tem à sua frente, como idealizador e roteirista, Miguel Falabella, celebridade da televisão brasileira, conhecido por suas ironias de classe, cujo efeito está mais para rir dos pobres do que com eles. As 
protagonistas, entretanto, são quatro atrizes negras desconhecidas do grande público. A série MB foi escrita por Jorge Furtado, importante cineasta, mas pouco conhecido do grande público televisivo. Os protagonistas desta série, ao contrário, formam um casal negro de reconhecida trajetória de sucesso também na televisão: os atores Lázaro Ramos e Taís Araújo, ambos ativos nas redes sociais com posturas antirracistas.

A série $\mathrm{SN}$, que procurou retratar a intimidade afetiva e sexual de quatro mulheres afrodescendentes da periferia do Rio de Janeiro, é uma paródia da série norte-americana Sex and the City. Mesmo antes da estreia, o programa gerou polêmica. O ponto principal dos debates enfatizou o caráter racista ou não do enquadramento temático do seriado. Em contrapartida, a série MB se propôs a tematizar a ascensão social, por meio da fama na carreira musical, de um jovem casal de negros. Esse sitcom não gerou polêmica na audiência, mas nele estão presentes, ainda que de forma sutil, as tensões interseccionais de gênero, raça e classe. Devido, ao menos em parte, às polêmicas, $\mathrm{SN}$ foi interrompido após a primeira temporada, enquanto MB teve quatro temporadas.

A controversa herança da representação televisiva brasileira dos afrodescendentes ecoa em ambas as séries. SN enfrenta o tema da autonomia sexual das mulheres negras diante dos constrangimentos advindos da cultura patriarcal, racista e marcada por profunda desigualdade de classe. O tema é complexo, pois nossa herança associa a sensualidade da mulher negra à sua submissão aos desejos do colonizador branco. MB, por sua vez, tematiza os conflitos raciais, sociais, de classe e culturais a partir da convivência do casal negro em ambientes típicos da elite branca. Sua abordagem, entretanto, parece mais sutil, talvez por suceder o polêmico seriado SN. Ambos os programas cruzam temáticas raciais, de gênero e de classe, logo, o olhar interseccional se mostra útil. Essa ferramenta favorece a valorização da interdependência dessas temáticas quanto aos seus efeitos de poder.

Os estudos sobre a representação de afrodescendentes nos programas de televisão do Brasil têm se pautado pelo diagnóstico da sub-representação e reprodução de estereótipos. Predomina a ideia de que a mídia contribui 
com a manutenção do racismo e evita colocá-lo na chave das relações de poder (Sodré, 1999; Borges, 2012; Araújo, 2000). Essas interpretações se amparam nos conceitos de ideologia e de dominação de classe. O paradigma dos efeitos é mobilizado num duplo sentido: os conteúdos transmitidos são efeito da dominação que a mídia busca encobrir, e esta teria efeitos poderosos sobre os dominados ao agendar temas com vieses favoráveis aos grupos dominantes. Esse debate ofereceu contribuições importantes, entretanto, algumas lacunas existem. É necessário aprimorar as explicações sobre o porquê de a televisão ter proposto, em diferentes momentos, como no caso dos seriados em tela, representar temas polêmicos com vieses, no mínimo, perpassados por tensões e contradições.

Avançar outras explicações requer um referencial que escape aos limites do paradigma dos efeitos e evite naturalizar a mídia ao atribuir-lhe a inescapável função de dominar as massas. Nesse sentido, mobilizaremos o olhar das "midiaculturas" (Maigret, 2010; Macé, 2006), analisando os seriados não a partir de seus supostos atributos essenciais (p. ex., reproduzir preconceitos e estereótipos com efeitos alienantes), mas entendendo-os como dispositivos construídos na interação com a sociedade e suas relações de força. As séries oferecem a oportunidade para observação das disputas discursivas, especialmente em torno da questão racial.

O conceito de "midiaculturas" agrega pensadores franceses que se inspiram nos Estudos Culturais ingleses, no construtivismo e na concepção de esfera pública polifônica. Essa perspectiva entende que a mídia interage com a sociedade buscando representar e agradar o público médio. Isto a torna, ao menos em parte, responsiva aos constrangimentos advindos do social (Porto, 2012). Colocar essa lente significa, também, valorizar a capacidade reflexiva dos públicos. Sendo assim, ao invés de buscar os "efeitos", este olhar se interessa pelos significados da universalização da experiência cultural pela mídia.

As questões que orientam a análise são: quais tensões permeiam, comparativamente, os conteúdos dos seriados quando se observa as linhas discursivas por eles mobilizadas, principalmente a respeito dos temas racial 
e de gênero? Quais linhas discursivas sobre gênero e raça são apropriadas pelos seriados e quais significados apresentam, comparativamente? Quais soluções narrativas os seriados propõem? Estas são questões que remetem à nossa herança discursiva marcada por linhas de força do tipo democracia racial, mestiçagem, branqueamento e machismo.

Este trabalho objetiva analisar comparativamente os conteúdos dos programas, procurando identificar traços de reprodução, apropriação e transformação das linhas discursivas que envolvem a intersecção entre raça e gênero. Nossa hipótese é de que os conteúdos dos seriados expressam tensões, mas também uma apropriação de linhas discursivas que apontam para novas práticas de normalização dos comportamentos e estabilização dos conflitos a partir da linguagem e do formato televisivo.

O corpus do trabalho é composto por conteúdos quantitativos retirados das cenas das duas séries. Os 13 episódios de SN foram segmentados em 457 partes, enquanto os 12 episódios da primeira temporada de MB apresentam 394 segmentos. De cada segmento, foram retiradas informações do tipo: protagonismo dos atores segundo o sexo e a cor, interlocução, tema predominante, viés dado ao tema, existência de conflito e predomínio dos atores no conflito (segundo o sexo e a cor). Esses dados compuseram uma planilha que foi processada no software SPSS, gerando frequências e cruzamentos. Devido aos limites deste artigo, conteúdos qualitativos das séries serão mobilizados de forma moderada, tais como o perfil dos personagens, o enredo e as linhas discursivas. Captar estatisticamente as imagens refletidas na TV não tem a pretensão de esgotar objetivamente as representações, mas faz parte do esforço de apreendê-las na sua reflexividade, ou seja, como construção a partir de pontos de vista cuja legitimidade está em disputa (Macé, 2009).

A parte a seguir do trabalho apresenta as linhas discursivas sobre raça e gênero, assim como o estágio atual do debate sobre a relação entre televisão, gênero e raça. Por fim, abordaremos as linhas teóricas que orientam nossa análise. A última parte abriga a análise comparativa dos conteúdos dos seriados. 


\section{O debate sobre raça, gênero e mídia}

As preocupações com os rumos da nação e a formação do povo estão na base das disputas discursivas sobre raça na nossa história recente. Por um lado, as proposições que apontavam para a homogeneidade do povo prevaleceram sobre aquelas que sugeriam a separação dos afrodescendentes em decorrência de suas supostas diferenças negativas que inviabilizariam o projeto de nação (Costa, 2009). A nação mestiça, nesta linha que vem de Gilberto Freyre (2006), poderia sim servir de base para o desenvolvimento da sociedade. Por outro lado, se faz presente também, e com vigor, uma linha discursiva que enfatiza a negatividade da herança mestiça gerada pelo padrão português de colonização, cuja procedência é Sérgio Buarque de Holanda. Esse passado pesaria por nos legar um "complexo de vira-lata", uma postura pré-moderna, pouco racional e muito emotiva. Racismo de marca e não de origem é um traço marcante da nossa herança (Nogueira, 2006). A linha discursiva da identidade nacional também fomenta a ideia de que a mistura das raças teria a capacidade de superar a suposta herança negativa africana graças ao embranquecimento do povo (Ortiz, 2006). A miscigenação, operando como pilar do mito fundador da nação, parece tentar ofuscar a violência sexual imposta às mulheres negras e indígenas pelos colonizadores brancos. tensão essa que não foi superada. A linha discursiva da mistura racial sofre apropriações e ressignificações no seu percurso histórico (Costa, 2009).

Um fenômeno interessante emerge no campo cultural a partir da narrativa que articula mestiçagem e branqueamento. A cultura afro compõe a identidade nacional e, sendo assim, é celebrada pelos brancos. Todavia, a cultura branca se mantém como experiência à parte, de um grupo que domina a economia e a política. Os brancos celebram a miscigenação desde que ela se mantenha apartada, sem ameaçar as hierarquias (Machado, 2002; Machado, 2012; Costa, 2009). Nessa chave conservadora, os discursos da mestiçagem e do branqueamento seguem potencializando o mito da democracia racial. É interessante sublinhar que o discurso conservador apela 
tanto para o argumento da diferença quanto para a igualdade. O apelo à igualdade das raças busca desarmar a articulação entre desigualdade social e racismo, enquanto a celebração da meritocracia justifica a diferença de acesso aos bens do mercado. Aliás, outro traço dessa hegemonia discursiva racial e de classe pode ser visto na valorização do mercado combinada com a desconfiança no Estado e na participação política popular.

As linhas discursivas descritas acima remontam à construção da hegemonia branca no século XIX (Munanga, 2008), entretanto, são ressignificadas conforme novas páginas dos conflitos são escritas. Abdias do Nascimento, ao denunciar o racismo, associou o slogan "branca para casar, preta para trabalhar e parda para fornicar" (apud Munanga, 2008) ao discurso da miscigenação. Percebe-se que raça, gênero e sexualidade têm papel importante nas controvérsias discursivas pela legítima identidade nacional. O vetor narrativo forte é o da "democracia racial" baseada na miscigenação e ratificada pelo sincretismo cultural. O racismo e o sexismo estão tão ligados que, ao pensar a mulher negra, a imagem é a da mulata e doméstica. A cultura brasileira negra é celebrada, mas sua africanidade e seu potencial de resistência são contidos, e retoma-se o mito da democracia racial "que exerce sua violência simbólica de maneira especial sobre a mulher negra" (Gonzales, 1984, p. 228).

As disputas discursivas raciais evidenciam um país ainda hoje marcado pelo racismo refletido nas desigualdades de oportunidades e na assimetria de direitos entre as raças. Contra a desconstrução científica a respeito das diferenças raciais, o racismo se reinventa em novas práticas políticas e sociais. E o senso comum ainda faz correlação entre atributos fenotípicos, beleza e inteligência (Schwarcz; Menezes Neto, 2016). Tendo em vista essas disputas discursivas, iremos observar os conteúdos dos seriados, todavia, convém fazer um breve balanço das discussões acadêmicas sobre mídia, raça e gênero.

Alguns autores analisaram a sub-representação dos afrodescendentes na TV brasileira e seu viés estereotipado (Sodré, 1999; Araújo, 2000). Segundo essa perspectiva, a TV e seu principal produto, a telenovela, reproduzem 
a ideologia do branqueamento e o mito da democracia racial. Entretanto, trata-se de uma história marcada por tensões. É interessante notar que o movimento negro obteve vitórias na luta contra a mídia (Araújo, 2000), o que referenda a tese de que esta é, ao menos em parte, responsiva às mobilizações da sociedade na esfera pública (Porto, 2012).

Estudos recentes atestaram a permanência da representação estereotipada de negras e negros na televisão (Alakija, 2012; Borges, 2012; Costa, 2012; Ferro, 2012). Todavia, essa literatura não se ocupa em explicar as mudanças e, até mesmo, as contradições que marcam os conteúdos televisivos a esse respeito. Essa postura dificulta a valorização da capacidade de agência dos públicos não hegemônicos e suas organizações.

Esther Hamburger, por exemplo, ao pensar a questão de gênero, percebe que a emergência da audiência televisiva no Brasil favoreceu o agendamento de temas femininos na esfera pública. Portanto, a mídia se oferece como instituição interessante para reflexão sobre subjetividades em disputa (Hamburger, 2007). A televisão mexeu com a rígida hierarquia entre público masculino e doméstico feminino ao embaçar essa fronteira. O caráter reflexivo da audiência, somado às ambiguidades da mídia, favorece a sua interação com a sociedade e, portanto, a geração de conteúdos que refletem as contradições e tensões sociais. Nesse sentido, as telenovelas promoveram o trânsito de conteúdos tidos como públicos em direção ao privado doméstico e vice-versa, provocando uma espécie de desencantamento do ambiente público masculino.

O referencial das "midiaculturas" valoriza o caráter interativo da mídia e, portanto, a apreensão das tensões e contradições dos seus conteúdos narrativos. A perspectiva francesa de "midiaculturas" se inspira nos Estudos Culturais ingleses, na Sociologia Construtivista e na concepção de "esfera pública polifônica" (Maigret, 2010). Ela se contrapõe à teoria crítica adorniana e ao consumo cultural bourdiano, pois valoriza as disputas interativas que perpassam a instituição midiática e envolvem um público com capacidade reflexiva. 
As disputas e controvérsias não são exclusivamente discursivas, mas, em grande medida, se expressam discursivamente, buscando, por exemplo, legitimar identidades. Mas não se deve entender o discurso, ou a representação, como efeito imaterial de uma realidade concreta (Morin, 2011). Morin explica que o atual, nossa vivência cotidiana, depende e é informado pelo virtual, nossa herança significativa. Portanto, atual e virtual compõem a realidade, e não faz sentido estabelecer uma hierarquia entre ambos. Discursos são práticas que operam nas interações cotidianas e que são por elas desafiados. Trata-se de um jogo tenso que envolve, por um lado, a reprodução dos quadros interpretativos do mundo e seu poder de estabilizar as relações e, por outro, os desafios e resistências que apontam para as transformações da sociedade (Macé, 2006).

O referencial acima descrito orientará a análise das linhas narrativas presentes nas séries televisivas, considerando a hipótese de apropriação e ressignificação da herança discursiva brasileira sobre raça e gênero. Interessa, portanto, observar a atualização dessas disputas discursivas, comparando o tipo de solução mobilizada em cada uma das séries. É instigante verificar como uma configuração discursiva se constitui buscando uma coerência estratégica, como ela opera tentando reproduzir regimes discursivos hegemônicos, mas transparecendo fissuras que denotam resistências. Nosso olhar irá privilegiar as intersecionalidades entre gênero e raça, entendendo intersectionalidade como uma ferramenta analítica "para apreender a articulação de múltiplas diferenças e desigualdades" (Piscitelli, 2008, p. 266).

O debate da interseccionalidade tem abordagens plurais. Crenshaw (2002) enfatiza as intersecções entre formas distintas de opressão, ou seja, uma mulher negra pode ser oprimida duplamente. Há uma crítica a essa formulação por valorizar a fragilidade na fusão entre diferença e desigualdade. Ou seja, gênero, raça e classe são vistos apenas como sistemas de dominação e marginalização que determinam identidades sujeitadas, vinculadas aos efeitos da subordinação social e do desempoderamento 
(Prins, 2006). Enfim, a noção de interseccionalidade de Crenshaw encontra seu limite na concepção de poder unilateral nas relações sociais.

A abordagem britânica, ou concepção construcionista de interseccionalidade (Brah, 2006; Prins 2006), não vê o poder como unilateral. Inspirada em Foucault, entende que existem conflitos e resistências. Outra distinção entre a abordagem sistêmica e construcionista é que a primeira assume uma noção de sujeito constituído por sistemas de dominação e marginalização. Para a segunda, os processos pelos quais os indivíduos se tornam sujeitos não se restringem à dominação, pois constituir-se sujeito envolve capacidade de agência. As classificações em gênero, classe e etnia são limitantes, mas também oferecem recursos capacitadores (Prins, 2006, p. 280); estas em parte limitam, mas também habilitam.

Na abordagem construcionista, a identidade não é somente nomeada, é narrada. Os indivíduos são atores e coatores de sua história de vida, mas a história de cada um pode ser criada apenas parcialmente por cada pessoa. Nessa perspectiva, a identidade é individual; pessoas com a mesma cor, gênero e classe têm experiências individuais diferentes, mas esses marcadores têm um influente papel (Prins, 2006, p. 281). Enfim, o que aparece na abordagem construcionista, e que a distingue das demais, é o poder de agência dos indivíduos.

Dalcastagnè (2014) ressalta a importância da conquista de espaço na representação cultural pelos marginalizados. A autora, portanto, argumenta na mesma linha de Araújo (2000), quando aponta a evolução positiva, ainda que contraditória, dos personagens negros na teledramaturgia brasileira. Visão compartilhada também por Hamburger (2007) ao indicar como as temáticas femininas ganharam o ambiente público através das telenovelas. Seja na literatura ou em programas televisivos, essa conquista "é um passo importante para a democratização de nossa vida cultural e de nossa vida urbana" (Dalcastagnè, 2014, p. 299). Entretanto, nosso olhar busca analisar criticamente de que forma se dá esse avanço na representação de públicos subalternos e qual o seu significado nas disputas por identidade. 


\section{Os seriados Sexo e as Negas e Mister Brau: um olhar comparativo}

Procederemos aqui à comparação entre os dois seriados. Para cumprir esse objetivo, analisaremos, principalmente, dados quantitativos referentes às narrativas.

SN foi exibido em uma única temporada de 13 episódios no segundo semestre de 2014. MB teve quatro temporadas entre 2015 e 2018. Apenas a primeira temporada, com 12 episódios, será objeto de análise nesse trabalho.

A inspiração para SN veio do seriado norte-americano Sex and the City. A ideia foi realizar uma espécie de paródia deste programa ambientado em Nova York, que tematizava com bom humor a vida afetiva e a sexualidade autônoma de quatro mulheres brancas de classe média. O autor de SN, ao que parece, quis representar positivamente a participação de mulheres negras da periferia urbana na experiência "moderna" da sexualidade feminina relativamente autônoma. Entretanto, o projeto cruzou conteúdos de identidade racial e de gênero de forma ambígua, ambos associados a experiências passadas e presentes de sexualidade. Mesmo antes da sua estreia, SN gerou polêmica nas redes sociais, especialmente nos sites e blogs ligados ao movimento negro. Falabella precisou rebater acusações de que o programa reproduzia o estereótipo racista da "mulata"1, objeto sexual a ser consumido pelo homem branco.

Ao dissociar gênero, raça e classe, o seriado SN não cumpre a promessa de valorizar a autonomia sexual das protagonistas; ao contrário, reforça o preconceito (Campos, 2014). A transposição da agenda de mulheres brancas da classe média nova-iorquina esbarra na herança discursiva que construiu a "mulata hiper-sexualizada", amante, poligâmica e submissa à violência machista do homem branco. Segundo Campos, o seriado americano enfrentou os estereótipos que ancoram a sujeição da mulher

1 A palavra mulata remonta à escravidão e à miscigenação. Ela é relacionada à mula que é um animal híbrido, estéril, produto do cruzamento do cavalo com a jumenta, ou da égua com o jumento. Sendo assim, o uso do termo para mulheres filhas do cruzamento interracial de brancos e negras pode ser visto como pejorativo. 
branca: monogamia e frigidez. O seriado brasileiro não soube traduzir a agenda crítica. Entretanto, nos parece que a intersecção dos temas feministas e racialistas na série apresenta outras tensões e contradições que merecem ser exploradas. Em muitas cenas, por exemplo, as personagens negras controlam a relação com os homens, inclusive brancos, exercendo, portanto, alguma autonomia quanto à sexualidade.

É interessante investigar como a disputa discursiva, que é uma disputa por identidade, se faz pela apropriação e ressignificação de narrativas, inclusive explorando brechas e mesclando sentidos. As quatro mulheres negras que a série SN propõe retratar são Matilde (Tilde), que vive de trabalhos esporádicos, principalmente como garçonete; Soraia, que é cozinheira; Zulma, que trabalha como camareira no teatro; e Lia, que não tem trabalho fixo. Tilde vive um longo e complicado relacionamento com um rapaz branco. Ela desfaz o namoro para seguir uma trajetória de estudos e crescimento pessoal que ele não acompanha. Ao final da série, Tilde vai estudar no exterior. Na sua volta ao Brasil, começa o namoro com um homem branco bem sucedido. Soraia vive situações de assédio no trabalho que são denunciadas com veemência. Sua trajetória é feita de várias relações, inclusive com uma experiência homoafetiva. Ao final ela obtém sucesso profissional com apoio da patroa com quem tem relações sexuais. Zulma vive um impasse entre seus relacionamentos amorosos e o desejo do seu pai de que ela case e constitua família. No seu percurso, ela se casa com um homem negro, colega de trabalho e tem um filho. $\mathrm{O}$ apoio dela se torna importante para que o marido cresça profissionalmente. Lia é separada, tem uma filha e uma neta, seu ex-marido, um homem branco, tenta controlar sua vida, ele é um traficante com grande poder na comunidade. Ao final, Lia vive um relacionamento estável com outro homem negro, escritor de livros infantis. O ambiente principal da série é uma comunidade popular, o morro de Cordovil.

Os seriados $\mathrm{SN}$, de modo mais explícito, e $\mathrm{MB}$, de maneira mais implícita, retomam conteúdos nevrálgicos da construção da identidade nacional: a sensualidade da mulher negra, a sexualidade interracial, o 
embranquecimento, a mestiçagem, o mito da democracia racial e o machismo, temas marcados por tensões e ambiguidades próprias das experiências interseccionais².

Em MB, o tema é a ascensão social, através da música, de um jovem casal de negros. Ele, representado pelo renomado ator Lázaro Ramos, é o protagonista cujo nome é Mister Brau, cantor e compositor de sucesso. Michele é coreógrafa e a produtora de Brau, além de ser sua mulher; a personagem é vivida pela atriz Taís Araújo, esposa de Lázaro Ramos. Com o sucesso musical, o casal ascende socialmente e vai morar num condomínio residencial de luxo, onde se passa a maior parte das cenas. O casal branco formado pelos personagens Henrique e Andreia é vizinho e principal interlocutor do casal Brau. Andreia manifesta preconceito de classe em relação aos vizinhos e, nas entrelinhas, preconceito racial. Henrique vira advogado de Brau e nutre um desejo platônico por Michele.

O conteúdo dos 13 programas do seriado SN foi dividido em 457 segmentos segundo o critério de mudança de assunto, ambiente e/ou de cena. Na série MB foram analisados os 12 episódios da primeira temporada. Utilizamos o mesmo critério para separação das cenas, assim, encontramos 394 segmentos.

Para cada segmento, foi aplicada uma planilha dividida em categorias analíticas que procuram identificar conteúdos, tais como: sexo e cor dos protagonistas e interlocutores na cena, temas principal e secundário tratados no segmento, viés dado ao tema, existência de conflito ou não no segmento e quem levou vantagem no conflito, também segundo sexo e cor dos envolvidos. O objetivo é verificar o que os números dizem sobre as séries e depois cruzar estas informações com a análise das disputas narrativas para uma melhor apreensão do conjunto das obras e de como elas se relacionam com a herança discursiva sobre raça e gênero no Brasil. Os dados quantificados foram rodados no software estatístico SPSS, que gerou as frequências e correlações.

2 Partilhamos da perspectiva crítica formulada por autores como Guimarães (1995), que denunciam o caráter mítico da democracia racial no Brasil. 
A tabela 1 nos informa sobre a frequência de protagonismo dos personagens, conforme a cor e o sexo. O critério adotado para conferir protagonismo ao personagem foi o seu predomínio no segmento, considerando uma combinação de critérios, apresentados a seguir em ordem crescente de importância: tempo de fala, proposição do tema, sucesso em estabelecer um viés e/ou vantagem no conflito.

Tabela 1 - Protagonistas (sexo e cor)

\begin{tabular}{|l|c|c|c|c|}
\hline \multicolumn{3}{|c|}{ Protagonistas } & \multicolumn{2}{c|}{ Protagonistas } \\
\hline Sexo e as Negas & \multicolumn{2}{c|}{ Mister Brau } \\
\hline Mulher negra & Frequência & Percentagem & Frequência & Percentagem \\
\hline Homem negro & 214 & $\mathbf{4 6 , 8} \%$ & 101 & $25,7 \%$ \\
\hline Mulher branca & 41 & $9,0 \%$ & 142 & $\mathbf{3 6 , 0} \%$ \\
\hline Homem branco & 150 & $32,8 \%$ & 67 & $17,0 \%$ \\
\hline Total & 52 & $11,4 \%$ & 84 & $21,3 \%$ \\
\hline
\end{tabular}

Fonte: Grupo de pesquisa Midiaculturas - UFPR.

No seriado SN, as mulheres negras tiveram o protagonismo na maior parte das cenas, em 46,8\% dos casos. Em relação ao protagonismo dos negros, somando homens e mulheres, o total é de 55,8\% de protagonismo no conjunto dos segmentos, contra $44,2 \%$ dos homens e mulheres brancas. Como visto na seção anterior, a herança midiática é negativa quanto ao tempo dedicado à representação dos negros e à relevância dos seus papéis, em especial, quando se trata das mulheres negras, portanto, não deixa de ser significativa a presença das personagens negras como protagonistas no seriado em tela. A situação de fala das mulheres negras está evidenciada, ou seja, os seriados em tela avançaram no que diz respeito a oferecer mais visibilidade e voz aos negros e, principalmente, às mulheres negras.

Comparativamente, é possível verificar que o seriado MB manteve o protagonismo dos personagens afrodescendentes, inclusive elevando um 
pouco este percentual, que atingiu $61,7 \%$ dos segmentos. Confirma-se a tendência verificada em SN, ou seja, mudar a herança de sub-representação das mulheres e homens negros nas telas de TV, ao menos nestes programas. Entretanto, inverteu-se a representação de gênero, o homem negro apareceu como protagonista em $36 \%$ das cenas de $\mathrm{MB}$, enquanto a mulher negra protagonizou 25,7\% dos segmentos. Mas, se considerarmos que SN tinha a proposição explícita de tematizar o protagonismo de quatro mulheres negras nas relações afetivas, pode ser considerado alto o protagonismo de pessoas brancas, como assinalado, de 44,2\%. Tanto mais se observarmos que dois brancos ocupam lugares de fala de destaque. O próprio autor, Miguel Falabella, é o narrador da história. A cada capítulo ele faz uma narração em off introduzindo temáticas e propondo enquadramentos normativos. A outra personagem branca com papel de destaque em SN é Jesuína, interpretada pela conhecida atriz Cláudia Jimenez. No início da trama, Falabella narra a história de criação da comunidade pelo avô de Jesuína. Além de participar desse "mito fundador", ela é responsável pela rádio comunitária, onde apresenta um programa e possui um bar, situações que a colocam no centro da maior parte das tramas da série. Sendo assim, ela divide com Falabella a tarefa de introduzir linhas discursivas nos episódios e também vieses. Trata-se de uma personagem de meia idade que vive um caso amoroso mal resolvido com um jovem negro. Individualmente, em SN, a personagem de Jesuína detém a maior frequência em protagonismo (16\%), seguida de Soraia (13,6\%), Zulma (11\%), Tilde (9,8\%) e depois Lia $(9,4 \%)$.

Considerando apenas a divisão por sexo, é preciso sublinhar que, em $\mathrm{SN}$, o protagonismo feminino é expressivo, perto de $80 \%$, enquanto os homens ocupam esta situação em apenas aproximadamente $20 \%$ dos segmentos. Já em MB, a herança hegemônica masculina se reproduz no quesito protagonismo. Eles ocupam esta situação em 57,3\% dos segmentos, enquanto as mulheres protagonizam $42,7 \%$ das cenas. Tendo em vista que o personagem central da série é masculino, a vantagem dos homens não chega a ser exagerada. 
Mas, com quem os protagonistas interagem preferencialmente? A tabela 2 ajuda a responder a questão sobre os principais pares de interação entre protagonistas e interlocutores em SN.

Tabela 2 - Protagonista x Interlocutor (sexo e cor) em Sexo e as Negas

\begin{tabular}{|c|c|c|c|c|c|c|c|}
\hline \multirow[b]{2}{*}{ Protagonista } & \multicolumn{6}{|c|}{ Interlocutor } & \multirow[b]{2}{*}{ Total } \\
\hline & Nenhum & $\begin{array}{c}\text { Mulher } \\
\text { negra }\end{array}$ & $\begin{array}{c}\text { Homem } \\
\text { negro }\end{array}$ & $\begin{array}{l}\text { Mulher } \\
\text { branca }\end{array}$ & $\begin{array}{c}\text { Homem } \\
\text { branco }\end{array}$ & Outros & \\
\hline Mulher negra & 12 & 54 & 53 & 37 & 55 & 2 & 213 \\
\hline Homem negro & 16 & 8 & 2 & 13 & 2 & 0 & 41 \\
\hline Mulher branca & 18 & 25 & 43 & 51 & 10 & 3 & 150 \\
\hline Homem branco & 30 & 10 & 2 & 8 & 2 & 0 & 52 \\
\hline Total & 76 & 97 & 100 & 109 & 69 & 5 & 456 \\
\hline
\end{tabular}

Fonte: Grupo de pesquisa Midiaculturas - UFPR.

No programa SN, considerando o sexo e a cor dos personagens, se destacam as mulheres brancas como interlocutoras em 109 cenas (23,9\%); muito próximos, aparecem os homens negros, com 100 segmentos (21,9\%) e, na sequência descendente, mulheres negras (21,3\%), seguidas de homens brancos (15,1\%). Os números em destaque na tabela indicam os maiores índices de interação. O par mais frequente foi o de mulher negra na situação de protagonista interagindo com homem branco como seu interlocutor, em 55 casos. Logo a seguir aparece o de mulheres negras protagonizando cenas com outras mulheres negras, em 54 dos segmentos; seguido de mulher negra como protagonista interagindo com homem negro como interlocutor em 53 casos. Mulher branca protagonista interagindo com mulher branca interlocutora também se destaca com 51 situações. Verifica-se uma distribuição muito próxima de interação entre esses pares. Finalmente, merece menção o grupo de mulheres brancas protagonistas interagindo com homens negros, com 43 casos. Como era de se esperar, tendo em vista os números do protagonismo para a série SN, é muito baixa a interação entre homens, sejam eles brancos ou negros. 
O mesmo dado para a série MB pode ser observado na tabela 3.

Tabela 3 - Protagonista x Interlocutor (sexo e cor) em Mister Brau

\begin{tabular}{|c|c|c|c|c|c|c|c|}
\hline \multirow[b]{2}{*}{ Protagonista } & \multicolumn{6}{|c|}{ Interlocutor } & \multirow[b]{2}{*}{ Total } \\
\hline & Nenhum & $\begin{array}{c}\text { Homem } \\
\text { negro }\end{array}$ & $\begin{array}{l}\text { Mulher } \\
\text { branca }\end{array}$ & $\begin{array}{c}\text { Homem } \\
\text { branco }\end{array}$ & $\begin{array}{l}\text { Mulher } \\
\text { branca }\end{array}$ & Outros & \\
\hline Homem negro & 4 & 31 & 19 & 50 & 37 & 2 & 143 \\
\hline Mulher branca & 1 & 10 & 6 & 45 & 6 & 1 & 67 \\
\hline Homem branco & 3 & 30 & 23 & 14 & 14 & 0 & 84 \\
\hline Mulher negra & 1 & 46 & 18 & 34 & 1 & 0 & 100 \\
\hline Total & 9 & 118 & 66 & 142 & 58 & 1 & 394 \\
\hline
\end{tabular}

Fonte: Grupo de pesquisa Midiaculturas - UFPR.

É possível destacar a situação de interlocutor do homem branco, com 142 segmentos nesta situação (36\%); na segunda posição está o grupo de homens negros, com 118 cenas (29,9\%). Bem mais atrás, aparecem as mulheres brancas, com 66 casos, e as mulheres negras, com 58 segmentos como interlocutoras. Verifica-se que o homem branco tem pouca presença como protagonista, mas se destaca como interlocutor, enquanto o homem negro aparece à frente como protagonista e bem posicionado como interlocutor. Confirma-se o maior espaço para os afrodescendentes, mas, principalmente, se eles são do sexo masculino. Se a mulher branca aparece pouco como protagonista em MB, em compensação, ela ultrapassa a mulher negra quando se trata de interlocução. De todo modo, o dado de interlocução confirma a maior presença masculina já verificada no protagonismo; eles aparecem como interlocutores em quase $66 \%$ dos casos. Novamente, em comparação com SN, a maior visibilidade da mulher é substituída, em MB, por mais presença dos homens.

Os dados sobre interlocução em MB refletem no emparceiramento das interações. Como era de se esperar, a maior interação se dá entre homens negros como protagonistas e homens brancos como interlocutores, com 
50 casos $(12,7 \%)$. Ligeiramente atrás e quase empatados vêm os pares mulher negra protagonista e homem negro interlocutor, com 46 casos $(11,7 \%)$, e mulher branca protagonista e homem branco interlocutor, com 45 segmentos do total de 394. Mulher negra com homem branco não é um par dos mais frequentes, ainda que mereça destaque, com 34 casos, seguido da interação homem negro e homem negro, observada em 31 dos segmentos. $\mathrm{O}$ último destaque é o par homem branco como protagonista e homem negro como interlocutor, com ocorrência em 30 casos.

Comparativamente, a mulher negra interagiu mais enquanto protagonista com outros pares em SN, na qual se destaca nas três primeiras posições. No seriado $M B$, a categoria mulher negra aparece apenas na segunda posição quanto a este critério. Em SN, destaca-se a interação interracial entre mulher negra protagonista e homem branco interlocutor. No caso de MB, a relação interracial que se destaca é entre homens negros protagonistas e homens brancos interlocutores. A mulher negra, por sua vez, aparece mais protagonizando cenas quando o homem negro é o interlocutor.

A tabela 4 nos permite observar a categoria dos protagonistas segundo o sexo e a cor em relação ao tema principal manifestado nos respectivos segmentos. O tema principal foi escolhido em função da sua preponderância no segmento, seja pelo critério da minutagem, seja por sua vinculação com o viés e/ou conflito quando estes apareciam no segmento.

Alguns números merecem destaque em SN. Dadas as características deste sitcom, não surpreende que o tema afetividade apareça em primeiro lugar, mas a vantagem é muito grande em relação aos demais. O segundo tema, que é cultura, tem uma frequência de quase um terço do assunto afetividade, enquanto o terceiro, a sexualidade, aparece com menos de um terço do primeiro tema, ainda que a série traga no título o apelo a este assunto.

Quando o tema é afetividade, o protagonismo das mulheres é grande e sem maiores diferenças entre negras (71 casos) e brancas (63 casos). Idem quando o tema é felicidade ou consumo. Mas, quando o tema principal é cultura, uma diferença significativa se apresenta: o protagonismo passa a 
ser da mulher branca, que aparece 28 vezes nesta situação, mais do que o dobro em relação às mulheres negras, que somam apenas 13 segmentos neste quesito. Salta aos olhos também o fato de as mulheres negras serem protagonistas quando o tema é sexualidade, numa proporção de quase cinco vezes mais do que as brancas, ou seja, 35 segmentos contra oito. Cenário muito parecido se revela quando o tema é o trabalho: mulheres negras aparecem com 28 casos e suplantam com boa vantagem as mulheres brancas e outros grupos. Merece destaque, ainda, o protagonismo quando o tema principal é "questão racial"; mesmo neste caso, as mulheres brancas estão à frente. Uma explicação para este fato está na existência de uma personagem branca, gaúcha, chamada Gaudéria, que vive na comunidade e expõe de forma contínua, pejorativamente e de modo caricatural, seu preconceito de classe e também racial.

Tabela 4 - Protagonista (sexo e cor) x tema principal no programa Sexo e as Negas

\begin{tabular}{|c|c|c|c|c|c|}
\hline \multirow[b]{2}{*}{ Tema } & \multicolumn{4}{|c|}{ Protagonista } & \multirow[b]{2}{*}{ Total } \\
\hline & $\begin{array}{c}\text { Homem } \\
\text { negro }\end{array}$ & $\begin{array}{l}\text { Mulher } \\
\text { branca }\end{array}$ & $\begin{array}{l}\text { Homem } \\
\text { branco }\end{array}$ & $\begin{array}{c}\text { Mulher } \\
\text { negra }\end{array}$ & \\
\hline Questão racial & 4 & 10 & 4 & 7 & 25 \\
\hline Sexualidade & 6 & 8 & 0 & 35 & 49 \\
\hline Machismo & 5 & 2 & 5 & 8 & 20 \\
\hline Feminismo & 1 & 6 & 2 & 5 & 14 \\
\hline Desigualdade & 0 & 3 & 2 & 11 & 16 \\
\hline Consumo & 2 & 14 & 7 & 16 & 39 \\
\hline Cultura & 5 & 28 & 11 & 13 & 57 \\
\hline Trabalho & 3 & 7 & 3 & 28 & 41 \\
\hline Felicidade & 1 & 6 & 1 & 8 & 16 \\
\hline Afetividade & 14 & 63 & 12 & 71 & 160 \\
\hline Total & 41 & 147 & 47 & 202 & 437 \\
\hline
\end{tabular}

Fonte: Grupo de pesquisa Midiaculturas - UFPR. 
Parece legítimo desconfiar que se reproduz em SN a linha discursiva que reserva à mulher negra papel principal na sexualidade e no trabalho, concebendo às brancas áreas como cultura e consumo. De todo modo, o seriado parece cumprir sua proposta quanto a colocar as mulheres negras no exercício de uma sexualidade autônoma, não subalterna. Mas vamos aguardar outros dados para tecer análises mais conclusivas. Os temas predominantes em relação ao protagonismo, no programa $\mathrm{MB}$, podem ser verificados na tabela 5 .

Tabela 5 - Tema principal x Protagonista (sexo e cor) no programa Mister Brau

\begin{tabular}{|c|c|c|c|c|c|}
\hline \multirow[b]{2}{*}{ Tema } & \multicolumn{4}{|c|}{ Protagonista } & \multirow[b]{2}{*}{ Total } \\
\hline & $\begin{array}{c}\text { Homem } \\
\text { negro }\end{array}$ & $\begin{array}{l}\text { Mulher } \\
\text { branca }\end{array}$ & $\begin{array}{c}\text { Homem } \\
\text { branco }\end{array}$ & $\begin{array}{c}\text { Mulher } \\
\text { negra }\end{array}$ & \\
\hline Questão racial & 6 & 7 & 4 & 5 & 22 \\
\hline Sexualidade & 8 & 4 & 7 & 9 & 28 \\
\hline Machismo & 16 & 1 & 4 & 4 & 25 \\
\hline Violência & 9 & 4 & 10 & 10 & 33 \\
\hline Feminismo & 0 & 0 & 0 & 2 & 2 \\
\hline LGBT & 3 & 0 & 0 & 3 & 6 \\
\hline Desigualdade & 3 & 2 & 1 & 1 & 7 \\
\hline Identidade/ & 3 & 7 & 3 & 28 & 41 \\
\hline status social & 6 & 10 & 4 & 8 & 28 \\
\hline Consumo & 17 & 9 & 7 & 9 & 42 \\
\hline Cidadania & 1 & 0 & 4 & 1 & 6 \\
\hline Cultura & 19 & 3 & 12 & 5 & 39 \\
\hline Trabalho & 24 & 6 & 8 & 15 & 53 \\
\hline Felicidade & 8 & 1 & 2 & 2 & 13 \\
\hline Afetividade & 13 & 17 & 13 & 23 & 66 \\
\hline Segurança & 9 & 4 & 8 & 3 & 24 \\
\hline Total & 142 & 68 & 84 & 100 & 394 \\
\hline
\end{tabular}

Fonte: Grupo de pesquisa Midiaculturas - UFPR 
Considerando que o seriado $\mathrm{MB}$ tem um formato próximo de $\mathrm{SN}$, o tema de maior frequência também é a afetividade, mas, neste caso, sem grande vantagem em relação aos assuntos que o sucedem. Em ordem decrescente de frequência, os principais são: trabalho, consumo, cultura, violência e, empatados, sexualidade e identidade.

A categoria protagonista da série, homem negro, entretanto, não lidera quando o tema é afetividade, seu protagonismo está associado aos temas trabalho, cultura, consumo e machismo. O personagem Brau ajuda a explicar esses números, pois ele aparece em muitas cenas cujo assunto é seu desempenho como cantor, compositor e músico; daí a alta frequência dos temas trabalho e cultura para homens negros. O que surpreende, entretanto, é esta categoria se sobressair protagonizando os temas do consumo e do machismo. Sobre isso, é possível afirmar que a ascensão do casal Brau é fortemente marcada pelo consumo. Aliás, este foi um traço dos últimos anos no Brasil pré-crise econômica, qual seja, a mobilidade social dos mais pobres, entre eles os negros, marcada principalmente pelo acesso ao consumo de bens antes restritos às classes média e alta. Quanto ao machismo, tanto o personagem Brau quanto Lima, amigo e parceiro musical, reproduzem a postura machista com frequência ao longo da primeira temporada da série. Merece destaque, ainda, a alta frequência de protagonismo das mulheres, negras e brancas, quando o tema é afetividade. Quanto ao assunto sexualidade, sua frequência foi moderada $(7,1 \%)$, mas, se comparada com SN $(11,2 \%)$, a diferença não é significativa. Todavia, o protagonismo quanto à sexualidade está distribuído de forma mais equilibrada entre as categorias de sexo e cor em MB do que em SN. Mesmo a vantagem dos afrodescendentes em relação aos brancos neste quesito não é significativa: a diferença é de 17 para 11 em números absolutos. Se o par temático "identidade e status social" teve frequência muito baixa em SN, a ponto de não aparecer na respectiva tabela, no seriado MB tem presença significativa. Mas, ainda que a distribuição de protagonismo quanto a este tema coloque a mulher branca, com dez casos, em ligeira vantagem sobre a mulher negra, oito situações, e esta acima do homem 
negro, em seis segmentos, deve-se considerar que a personagem Andreia aparecia em muitas situações protagonizando o discurso de preocupação ou afirmação do seu status social em contraposição aos novos vizinhos, o casal Brau. Por outro lado, o personagem Brau protagonizou algumas cenas de um discurso explícito de afirmação da identidade negra.

\section{Considerações finais}

Ao analisar comparativamente o conteúdo das duas séries chegamos a algumas considerações que dialogam com a literatura que utilizamos. Começando pelo protagonismo, é correto afirmar que ambos os seriados invertem a herança de sub-representação de afrodescendentes na televisão, entretanto, no programa Mister Brau (MB), inverteu-se o protagonismo das mulheres negras observado no seriado Sexo e as Negas (SN).

Quanto à interlocução, o par mais frequente em SN foi o de mulher negra na situação de protagonista interagindo com homem branco. Como as mulheres negras são protagonistas nos temas afetividade e sexualidade, percebe-se a retomada da linha discursiva que envolve a relação interracial entre mulheres negras e homens brancos, mas, em $\mathrm{SN}$, com o predomínio da mulher negra, como atesta o conjunto dos dados.

Em MB, a interlocução tem maior frequência no grupo dos homens brancos, mas seu par é com os homens negros na condição de protagonistas. A linha discursiva da sexualidade interracial não chega a ser abandonada, mas é atenuada. De todo modo, confirma-se o maior espaço para os afrodescendentes, mas, principalmente, se eles são do sexo masculino.

Sexualidade e trabalho são temas de destaque para as mulheres negras em SN, enquanto as brancas atuam mais em cultura e consumo. Se por um lado, SN cumpre a promessa de protagonismo da mulher negra no exercício autônomo da sexualidade, por outro, valoriza, ao menos em termos quantitativos, a linha discursiva que distancia a mulher negra de temas como a cultura. Na intersecção entre gênero e raça, verifica-se, portanto, uma tensão: de um lado, se reproduz a matriz discursiva que associa a mulher 
negra à sexualidade, mas, por outro, a agência das mulheres negras se faz presente ao protagonizarem as cenas com relativa autonomia.

Não deixa de ser surpreendente que, em MB, os homens negros se destaquem em temas como consumo e machismo. A ascensão do casal Brau não vem acompanhada de uma crítica ao consumismo, mas da sua integração ao consumo, acompanhando o processo vivido na sociedade brasileira. O personagem de Brau, nas suas ambiguidades, expressa um comportamento machista, principalmente na forma do assédio malicioso.

Os dois seriados tratam da questão racial, mas com algumas diferenças. Em SN, observa-se uma ressignificação da linha discursiva "democracia racial". O preconceito é democratizado, pois todos, independentemente de cor, podem expressar preconceito racial. Nessa mesma linha, promoveuse uma equivalência entre o preconceito racial e outros preconceitos. $\mathrm{O}$ mais importante, todavia, foi a ressignificação da sexualidade interracial. A mulher negra passa ao protagonismo nessa relação e usa seu poder de sedução para pacificar os conflitos associados à questão racial. Em várias cenas, o pedido de desculpas do homem, branco ou negro, pelo preconceito contra a mulher negra é aceito na forma de relação sexual conduzida por ela. Desse modo, mais uma vez, a intersecção entre raça e gênero como estratégia de subalternização é, em parte, reproduzida, mas, também em parte, sofre resistência. A mulher negra não politiza o racismo, mas é a agente da sexualidade que pretende pacificar o conflito.

Em MB, a questão racial aparece de modo menos explícito e pouco associado à sexualidade. $\mathrm{O}$ personagem Brau exerce uma resistência ao preconceito racial, mas na forma da malícia e da malevolência. Ao fazêlo, reintroduz uma linha discursiva conservadora, qual seja, a ideia de que as classes populares e, particularmente os negros, se comportam de uma forma pré-moderna, pautada na malandragem. Sob essa perspectiva, percebemos a reprodução de uma narrativa negativa na representação televisiva do homem negro, pois ele não aparece como sujeito de direito, mas como aquele que revida a injustiça pela malandragem. De todo modo, ele é representado como o sujeito que resiste. 
Em MB, a cultura negra é valorizada, assim como a identidade, mas sem que ela sirva para questionar as desigualdades e injustiças contra negros e pobres. Ou seja, retoma-se a linha discursiva que valoriza a cultura negra como patrimônio nacional, sem que isso implique em empoderamento político, econômico ou social. Nas suas tensões, MB explicita o comportamento de uma elite interesseira, que expressa preconceito de classe e racial, mas, para atingir objetivos como status social, se aproxima estrategicamente de negros bem sucedidos. Quanto à sexualidade interracial, em MB, ela é sublimada. Negros assediam as brancas expondo seu machismo e brancos, em posição subalterna, fantasiam com a sensualidade das negras, mas em geral a relação não se concretiza; faz presença uma linha de valorização da tradição familiar e da fidelidade. Os dois lados parecem convergir para um comportamento comedido, onde predomina a racionalidade sobre a sensibilidade. O principal ponto dessa convergência parece ser a celebração do consumo e da alegria proporcionada pela dimensão cultural animada pela música. Diferente de SN, em MB a solução para a herança racial não é a inversão dos papéis sexuais interraciais, mas a contenção do desejo sexual em favor do comportamento mais racional, ainda que permeado pela alegria cultural coletiva.

Em resumo, no conjunto de dados associados ao relacionamento afetivo e sexualidade, $\mathrm{SN}$ teve um desempenho menos conservador e pejorativo do que MB. Entretanto, MB valorizou mais o conflito e a contestação.

Por fim, os dados referentes ao conflito confirmam a vantagem afrodescendente. Surpresa é o predomínio das mulheres negras e do gênero feminino, como um todo, nas situações de disputa em MB, na contramão de outros dados dessa série. Em SN, as mulheres negras são responsáveis por imprimir vieses mais progressistas aos temas, o que pode ser interpretado como uma capacidade de agência interseccional, principalmente por mostrar experiências distintas de mulheres da mesma raça e classe. Todavia, o comportamento geral dos agrupamentos em MB é mais conservador do que em SN. 
Avanços foram identificados na forma de retratar especialmente as mulheres negras, sobressaindo o protagonismo delas em SN e o poder de contestação em MB. Entretanto, conteúdos reprodutores de representação estereotipada também estiveram presentes, como a mulher negra objetificada e ocupando profissões subalternas, ou o homem negro como malandro. Em resumo, a representação televisiva parece acompanhar as tensões e contradições das questões raciais e de gênero presentes na sociedade brasileira contemporânea.

Nelson Rosário de Souza é professor titular na área de Ciências Sociais na Universidade Federal do Paraná.

$\bowtie$ nrdesouza@uol.com.br

Daniela Rocha Drummond é doutoranda em Ciência Política na Universidade Federal do Paraná e Mestre em Ciência Política.

$\triangle$ daniela.imprensacwb@gmail.com

Viritiana Aparecida de Almeida é doutoranda em Ciência Política na Universidade Federal do Paraná e Mestre em Ciência Política.

$\triangle$ viritianaalmeida@gmail.com

\section{Referências}

1. ALAKIJA, Ana. Mídia e identidade negra. In: BORGES, Roberto; BORGES, Rosane (Orgs.). Mídia e racismo. Petrópolis: DP et alii, 2012. p. 106-151.

2. ARAÚJO, Joel Z. A negação do Brasil: o negro na telenovela brasileira. São Paulo: SENAC, 2000.

3. BRAH, Avtar. Diferença, diversidade, diferenciação. Cadernos Pagu, n. 26, p. 329-376, jan./jun. 2006. https://doi.org/10.1590/S0104-83332006000100014.

4. BORGES, Rosane. Mídia, racismos e representações do outro: ligeiras reflexões em torno da imagem da mulher negra. In: BORGES, Roberto; BORGES, Rosane (Orgs.). Mídia e racismo. Petrópolis: DP et alii, 2012. p. 178-203.

5. CAMPOS, Luiz Augusto. As "negas" in the city? Paroxismo de uma importação dramatúrgica. O blog do Démodé, 5 dez 2014. Disponível em: < http://grupodemode.tumblr.com/post/104405795722/as-negas-in-the-city-paroxismo-deuma $>$. 
6. COSTA, Kátia R. De quando a pluralidade revela a invisibilidade. In: BORGES, Roberto; BORGES, Rosane (Orgs.). Mídia e racismo. Petrópolis: DP et alii, 2012. p. 40-63.

7. COSTA, Rosely. Mestiçagem, racialização e gênero. Sociologias, v. 11, n. 21, p. 94-120, jan./jun. 2009. https://doi.org/10.1590/S1517-45222009000100006

8. CRENSHAW, Kimberlé. Documento para o encontro de especialistas em aspetos da discriminação racial relativos ao género. Estudos Feministas, v. 10, p. 171188, 10 semestre, 2002. https://doi.org/10.1590/S0104-026X2002000100011.

9. DALCASTAGNÈ, Regina. Para não ser trapo no mundo: as mulheres negras e a cidade na narrativa brasileira contemporânea. Estudos de Literatura Brasileira Contemporânea, n. 44, p. 289-302, jul./dez. 2014. https://doi.org/10.1590/231640184413.

10. ESQUENAZI, Jean-Pierre. As séries televisivas. Lisboa: Texto \& Grafia, 2011.

11. FERRO, Rogério. O negro sem cor no telejornalismo brasileiro. In: BORGES, Roberto; BORGES, Rosane (Orgs.). Mídia e racismo. Petrópolis: DP et alii, 2012. p. 64-83.

12. FREYRE, Gilberto. Casa grande \& senzala: formação da família brasileira sob o regime da economia patriarcal. 51. ed. rev. São Paulo: Global Editora, 2006.

13. GONZALES, Lélia. Racismo e sexismo na cultura brasileira. Revista Ciências Sociais Hoje, Anpocs, n. 2, p. 223-244, 1984.

14. GUIMARÃES, Antonio Sérgio. "Raça", racismo e grupos de cor no Brasil. Revista Estudos Afro-Asiáticos, n. 27, p. 45-63, 1995.

15. HAMBURGER, Esther I. A expansão do "feminino" no espaço público brasileiro: novelas de televisão nas décadas de 1970 e 80 . Revista Estudos Feministas, v. 15, n. 1, p. 153-175, 2007. https://doi.org/10.1590/S0104-026X2007000100010

16. HAMBURGER, Esther I. Telenovelas e interpretações do Brasil. Lua Nova, São Paulo, v. 82, p. 61-86, 2011. Disponível em: https://www.redalyc.org/articulo. oa?id=67318715004

17. MACHADO, Igor. Mestiçagem arqueológica. Estudos Afro-Asiáticos, n. 2, p. 385-408, 2002. https://doi.org/10.1590/S0101-546X2002000200007.

18. MACHADO, Sátira. Infância e negritude: cidadania e afrodescendentes no Brasil. In: BORGES, Roberto; BORGES, Rosane (Orgs.). Mídia e racismo. Petrópolis: DP et alii, 2012. p. 206-244.

19. MACÉ, Éric. Mesurer les effets de l'ethnoracialisation dans les programmes de télévision: limites et apports de l'approche quantitative de la " diversité ». Reseaux, Paris, v. 5-6, n. 157-158, p. 233-265, 2009.

20. MACÉ, Érić. Les imaginaires médiatiques: une sociologie postcritique des médias. Paris: Éditions Amsterdam, 2006. 
21. MAIGRET, Éric. Sociologia da comunicação e das mídias. São Paulo: Editora Senac, 2010.

22. MORIN, Edgar. Cultura de massas no século XX: o espírito do tempo 1: neurose. Rio de Janeiro: Forense Universitária, 2011.

23. MUNANGA, Kabengele. Rediscutindo a mestiçagem no Brasil: identidade nacional versus identidade negra. Belo Horizonte: Autêntica, 2008.

24. NOGUEIRA, Oracy. Preconceito racial de marca e preconceito racial de origem. Tempo Social, v. 19, n. 1, p. 287-308, nov. 2006.

25. ORTIZ, Renato. Cultura brasileira e identidade nacional. 5. ed. São Paulo: Brasiliense, 2006.

26. PORTO, Mauro. Media power and democratization in Brazil: TV Globo and the dilemmas of political accountability. Nova York: Routledge, 2012.

27. PRINS, Baukje. Narrative accounts of origins: a blind spot in the intersectional approach? European Journal of Women's Studies, v. 13, n. 3, p. 277-290, 2006.

28. PISCITELLI, Adriana. Interseccionalidades, categorias de articulação e experiências de migrantes brasileiras. Sociedade e Cultura, n. 2, p. 263-274, jul./ dez. 2008. https://doi.org/10.5216/sec.v11i2.5247

29. SODRÉ, Muniz. Claros e escuros: identidade, povo e mídia no Brasil. Petrópolis: Vozes. 1999.

30. SCHWARCZ, Lília; MENEZES NETO, Hélio. Quando o passado atropela o presente: notas de um Brasil que insiste no racismo. Revista Cadernos de Campo, v. 25, p. 31-35, 2016. https://doi.org/10.11606/issn.2316-9133.v25i25p31-35

Recebido: 8 jul. 2019.

Aceito: 30 mar. 2020. 
